\title{
Water vapour sorption thermodynamic properties and stability of spray dried avocado milkshake powder
}

\author{
VK Shiby ${ }^{1}$, KS Babu $^{2}$, P Thorakkattu ${ }^{2}$ and MC Pandey ${ }^{1}$
}

Received: 25 August 2021 / Accepted: 17 February 2021 / Published online: 27 July 2021

(C) Indian Dairy Association (India) 2021

\begin{abstract}
Correlation of sorption and glass transition properties were determined for avocado milkshake pulp powder obtained by spray-drying with varying levels $(2,6,12 \%)$ of maltodextrin (MD). The isotherms were Type III, and GAB model was found to be adequate to predict the sorption data. At $25^{\circ} \mathrm{C}$, the critical water content that ensures the glassy state of the shake powder during storage increased from 0.05 to $0.08 \mathrm{~g}$ water $/ \mathrm{g}$ product while the critical water activity increased from 0.14 to nearly 0.6 , yield increased, and stickiness decreased with increasing levels of MD. ( 2 to $12 \%)$. The correlation between glass transition temperature (Tg) and the water fraction present in the sample was fitted using the Gordon-Taylor model showing satisfactory values of $\mathrm{R}^{2}(0.89)$. From the combined plot of $\mathrm{Tg}$ and equilibrium moisture content versus water activity, the critical water activity at $20^{\circ} \mathrm{C}$ is 0.1 , which increased to 0.6 at $-5^{\circ} \mathrm{C}$.
\end{abstract}

Keywords: Avocado, Spray drying, Sorption, Glass transition temperature, Stability

\section{Introduction}

Among all the fruits, the avocado (Perseaamericana)is a fat-rich fruit mainly consumed fresh. Itis known for its pleasing taste and predominance of monounsaturated fatty acids (Duester, 2000). It is also recognized as a functional food containing healthpromoting phytochemicals such as glutathione and betasitosterol (Rainey et al. 1994). Additionally, avocado is a good

${ }^{1}$ Defence Food Research Laboratory, Siddharthanagar Mysore-570011, India

${ }^{2}$ Department of Animal Sciences and Industry/ Food Science Institute, Kansas State University, Manhattan, KS 66506, USA

VK Shiby $(\bowtie)$

Freeze drying and Animal Products Technology Division, Defence Food Research Laboratory, Siddharthanagar Mysore-570011, India E-mail:shibyk@gmail.com source of vitamins(A, B, C, E), minerals (potassium, phosphorus, magnesium, calcium, sodium, etc.), and fibre, offering significant health benefits. The preservation of avocado is a challenge to the food technologists due to browning and heat-induced sensory changes in the product. In order to increase commercialization on a large scale and give avocado an added value, it is essential to develop food products derived from this fruit with a shelf life long enough for their transportation and distribution to consumers (Dorantes et al. 2004).

Due to the growing market of dairy companies, there has been a merging of dairy products and fruit beverage markets, introducing hybrid dairy products that offer health, flavour, and convenience. Instant dairy mixes like milk powders, dry ice cream mix, and lassi powder do not contain phytonutrients. Very limited studies have reported the value addition and utilization of avocado in dairy products. There is a great scope for developing spray-dried dairy mixes fortified with phytonutrients derived from avocado pulp with suitable additives to reduce stickiness and heat-induced bitterness.

Drying produces a stable, easy-handling form that reconstitutes rapidly to a good quality product resembling the original one as close as possible. Nevertheless, drying of fruit juices and other high sugar content products with introduces practical complexities due to its thermoplasticity and hygroscopicity at high humidities and temperatures (Adhikari et al. 2004; Gabas et al. 2007). Consequently, the addition of maltodextrin (MD) and gums alongside other additives such as calcium silicate, carboxymethyl cellulose, and pectin has been used in the production of powder juices (Bhandari et al. 2005). These characteristics are attributed to lower molecular weight sugars such as fructose, glucose, sucrose, and organic solids such as citric, malic, and tartaric which are major solids in fruit juices. The low glass transition temperature $\left(\mathrm{T}_{\mathrm{g}}\right)$, high hygroscopicity, high water solubility and low melting point of these solids lead to a highly sticky product when spray-dried. The drying carriers or aides are compounds with high molecular weight that have high $\mathrm{T}_{\mathrm{g}}$; accordingly, they can raise the $\mathrm{T}_{\mathrm{g}}$ value of feedstuff and the resultant powder (Shrestha et al. 2007). The hygroscopicity problems and thermo plasticity happening in drying of dairy- 
based or fruit juice with high sugar content can be overcome by adding some carriers such as MD and Arabic gum (Cano Chauca et al. 2005), waxy starch, etc. MDs have high water solubility and are mainly used in materials that are difficult to dry (Reineccius, 1991) and to reduce stickiness and agglomeration problems during storage, thereby improving product stability (Silva et al. 2006). Sugar and tricalcium phosphate were found to enhance the flowability of powders with high-fat content (Shivakumar et al. 2012). The fat in the cream powder was encapsulated by lactose or maltodextrin, and casein resulted in cream powder with good emulsion properties and solubility as those of the cow milk powder(Xiong et al.2004).Moisture sorption isotherms illustrate the relationship between water activity and equilibrium moisture content of a food product. Familiarity of water sorption isotherms and isosteric heat of sorption is of essential importance to numerous food processes such as storage, drying, and packaging since they are used to calculate drying time, to predict ingredients behaviour upon mixing, packaging selection, modelling moisture changes that occur during storage, and estimating shelf-life stability, which is very important mainly for food powders. These properties give information about the interactions between food components and the water sorption mechanism. They also help to establish the final moisture content and permit the estimation of energy requirements of the drying process.

Numerous mathematical models for the description of foods moisture sorption behaviour are available. Some of these models are based on theories on the sorption mechanism; others are purely empirical or semi-empirical. The principles used to select the most appropriate sorption model are the degree of fitting of experimental data and the physical meaning of the model. Recently, the concepts related to water activity have been coupled with those of the glass transition temperature, $\mathrm{Tg}$, providing an integrated approach to the role of water in foods. The glass transition is defined as the temperature at which an amorphous system changes from the glassy state to the rubbery state. Molecular mobility in the glassy state is extremely slow due to the high viscosity of the matrix (about $10^{12} \mathrm{~Pa} \mathrm{~s}$ ). Therefore, the $\mathrm{Tg}$ can be taken as a reference parameter to characterize the properties, quality, stability and safety of food systems. Structural alterations, such as stickiness, agglomeration, caking and crystallization, occur in amorphous food powders when stored at temperatures above the Tg. Foods with low-moisture contents and $\mathrm{Tg}$ value above the storage temperature can be considered stable. However, a slight increase in moisture significantly reduces the Tg. Therefore, the moisture sorption and Tg supply critical values for the water activity and moisture content at room temperature (Khalloufi et al. 2000; Roos1995; Roos and Karel, 1991).

The aim of the present work was to evaluate the influence of varying levels of maltodextrin on the physical properties, water sorption, $\mathrm{Tg}$, and stability of spray-dried avocado milkshake powder. Modeling of the sorption isotherms and Tg using selected models from the literature was studied, and attempts were made to couple sorption data with $\mathrm{Tg}$ for better prediction of the stability of the product.

\section{Materials and Methods}

\section{Materials}

Avocados were purchased from a local market (Mysore, India). The avocados were stored in a cold chamber at $4{ }^{\circ} \mathrm{C}$ and thawed according to the quantity required to produce the spray-dried milkshake powder. Milk was procured from Nandini Dairy (Mysore, India). The carrier agent used was Maltodextrin (DE 10), procured from Pristine Organics, Bangalore.

\section{Preparation of avocado milkshake}

Avocados (Persea americana Mill.) were washed, disinfected with Potassium permanganate. Then the pulp was separated from the peel using a sterilized knife. The extracted pulp was ground in a mixer-grinder. The fine ground pulp was homogenized with milk along with powdered sugar, and carrier material maltodextrin (DE 10) was added at the rate of 2,6 , and $12 \%$ of the blend containing milk and avocado pulp. Sugar was added at the rate of $10 \%$.

\section{Spray drying}

Milkshake was prepared by mixing milk and pulp in the ratio 3:1 with the addition of $10 \%$ sugar. Maltodextrin (DE 10) was added at 2, 6 and $12 \%$ of the milk shake blend without sugar. The spray drying process was performed using a laboratory spray dryer (S.M Scientific, Kolkata). The dryer was equipped with a spray nozzle with an orifice of $0.7 \mathrm{~mm}$ in diameter. The avocado milkshake was fed into the drying chamber using a peristaltic pump. The inlet air temperature was $175^{\circ} \mathrm{C}$, and the outlet air temperature varied from 90 to $100^{\circ} \mathrm{C}$ for each sample. The feed pump rpm was 20 , feed rate was $500 \mathrm{ml}$ per hour and the blower speed was 2350 rpm during the spray drying process. The compressed air pressure was maintained between $2-3 \mathrm{~kg} / \mathrm{cm}^{2}$ corresponding to air flow rate of $0.66-1.33 \mathrm{CFM}$.

\section{Proximate analysis}

The samples with varying levels of MD were taken and analyzed for moisture, protein, and fat according to the AOAC, 2005 methods. Moisture and protein determinations were performed in triplicates, and single fat analysis was conducted for each sample. The powder sample $(5-10 \mathrm{~g})$ was incinerated in a muffle furnace at $550^{\circ} \mathrm{C}$ for $3-4$ hours to determine the ash content.

\section{Modelling of sorption isotherms}

Sorption isotherms were determined by means of the gravimetric method. The initial moisture content in powder samples were 
determined by drying in a vacuum oven (Ranganna, 2004). Two to three grams samples of powder filled in sterilized glass bottle weighing dishes were placed in six separate desiccators containing saturated salt solutions for maintaining relative humidity (RH) levels from 11 to $85 \%$. The six jars were placed in an oven adjusted to a stable temperature for $24 \mathrm{~h}$ in order to bring the salt solutions to a constant temperature. Triplicate samples were used ( $2-3 \mathrm{~g}$ each) equilibrated over saturated salt solutions (1, providing relative humidity values of $11.15 \%, 32.73 \%, 43.80 \%$, $52.86 \%, 75.32 \%$ and $84.32 \%$, respectively in desiccators at $25^{\circ} \mathrm{C}$ until equilibrium. The air inside the desiccators was removed with the help of a vacuum pump. A glass dish containing $5 \mathrm{ml}$ toluene was placed in desiccators with relative humidity higher than $75 \%$ to check mold growth. The samples were weighed periodically till they attained equilibrium, after which they were analyzed for moisture content. To establish moisture sorption isotherms, the equilibrium moisture contents, determined by static gravimetric method, were plotted against water activity. The hygroscopic equilibrium of samples was reached in 7-10 days. The equilibration moisture content in samples were determined by subtraction method and expressed as $\mathrm{g}$ water/ $100 \mathrm{~g}$ solids. To establish moisture sorption isotherms, the equilibrium moisture contents were plotted against water activity. The physical appearance of the samples was also observed to check whether the powder had suffered any transformation such as agglomeration, caking or collapse.

Several models (empirical, semi-empirical, and theoretical) with two or more parameters have been used in the literature to describe the sorption isotherms. Equations based on sorption theories, such as BET and GAB models, are usually preferred by most researchers, since some physical meaning may be attached to their parameters, aiding in the understanding of the water sorption phenomena. Derived by simple extension and generalization of Langmuir's theory of unimolecular adsorption, the classic BET Eq. (1) (Brunauer et al. 1938) is a two-parameter model assuming the condensation of an infinite number $n$ of layers from the vapor phase onto the adsorbent surface.

$$
\text { Eq. }(1)^{X e}=\frac{X m C a w}{\lfloor(1-a w)(1-a w+C a w)\rfloor}
$$

Xe: equilibrium moisture content ( $\mathrm{g}$ water/g dry matter), Xm: monolayer moisture content ( $\mathrm{g}$ water/g dry matter), $\mathrm{a}_{\mathrm{w}}$ : water activity, C: constant of BET.

GAB model shown in Eq 2 was also used to fit experimental data.

$$
\text { Eq. }(2) X e=\frac{X m C K a w}{\lfloor(1-K a w)(1-K a w+C K a w)\rfloor}
$$

Xe: equilibrium moisture content ( $\mathrm{g}$ water/g dry matter), Xm: monolayer moisture content ( $\mathrm{g}$ water/g dry matter), $\mathrm{a}_{\mathrm{w}}$ : water activity, $\mathrm{K}$ and $\mathrm{C}$ : constant of GAB and BET, respectively.

In order to obtain the model parameters, a non-linear regression analysis was carried out using the Graphpad Prism (USA) software package. The degree of fitness of each model was evaluated by the determination coefficient and mean relative deviation modulus E

$E=\frac{100}{N} \sum_{i=1}^{N} \frac{|V \varepsilon-V p|}{V \varepsilon} \mathrm{Eq} .(3)$

$\mathrm{N}$ : population of experimental data, Ve and Vp: experimental and predicted value, respectively.

\section{Glass transition temperature}

About $10 \mathrm{mg}$ of avocado milkshake powder were placed into differential scanning calorimetry (DSC) aluminum pans, which was equilibrated over saturated salt solutions in desiccators at $25^{\circ} \mathrm{C}$ until equilibrium was reached. The samples were then hermetically sealed with lids for analysis and weighed. The mass of each sample pan was matched in advance with the mass of an empty reference pan to within $\pm 0.1 \mathrm{mg}$. The DSC analyses were carried out in a TA-MDSC-2920 (Ta Instruments, New Castle, De, USA). For temperatures below $70^{\circ} \mathrm{C}$, liquid nitrogen was used. After cooling the sample to $-30^{\circ} \mathrm{C}$, the glass transition temperature was determined on thermo-analytical curves obtained by heating the sample at $10^{\circ} \mathrm{C} / \mathrm{min}$ up to $110^{\circ} \mathrm{C}$ (or other values for the initial and final temperatures, according to the sample). The second scanning of each sample was performed to reduce the enthalpy relation of the amorphous powder, which appears in the first scan. All analyses were done in triplicate and the data were treated by the software Universal Analysis 2.6 (TA Instruments, New Castle, De, USA).

To describe the plasticizing effect of water on avocado milkshake powder, the glass transition temperature data were fitted to the Gordon-Taylor model (Gordon and Taylor, 1952)

$$
T g=\frac{W g T g s+k W w T g w}{W s+K W w} \mathrm{Eq} .(4)
$$

W: weight fractions (g/g total), s: solids, w: water, Tg: glass transition temperature $\left({ }^{\circ} \mathrm{C}\right)$, $\mathrm{k}$ : constant.

The $\operatorname{Tg}_{\mathrm{w}}$ value was taken at $135^{\circ} \mathrm{C}$ (Johari et al. 1987).A nonlinear regression analysis was carried out using the Graph Pad 
Prism (Ohio, USA) software package to obtain the model parameters $\mathrm{k}$ and Tgs.

\section{Results and Discussion}

\section{Proximate composition and quality characteristics of spray- dried avocado milkshake}

Fresh avocado showed moisture content in the range of $65-75 \%$, total acidity of $1.02 \pm 0.39 \%$ (as citric acid content), and $\mathrm{pH} 6.38 \pm$ 0.02 , respectively. The fresh pulp had a total solid content of 8 $9{ }^{\circ}$ Brix. The milk used in formulation of butter fruit milkshake (BFMS) samples contained 3\% fat and $8.5 \%$ SNF. The proximate composition of BFMS before drying are shown in Table 1.

\section{Spray dried avocado milkshake powder}

Spray dried avocado milk shake (BFMS-SD) powder containing varying level of MDs were evaluated for colour, water activity, sorption behaviour and glass transition temperature. BET and GAB models were used to fit the experimental sorption data, and the monolayer moisture content in spray-dried samples were estimated as parameters of these models. DSC was used as a tool to evaluate the $\mathrm{T}_{\mathrm{g}}$ and endothermic and exothermic phase transitions in the products over a range of -30 to $110^{\circ} \mathrm{C}$.

\section{Colour values and water activity}

$L^{*}, a^{*}, b^{*}$ values and water activity of fresh and spray dried avocado milkshake containing varying levels of maltodextrin (MD) were estimated using Hunter lab colourimeter, and the results are shown in Table 2. Color values of BFMS-SD powders differed significantly from the colour values of fresh avocado pulp (data not shown). With increasing level of MD there was slight variation in values, but there was no specific trend observed. The BFMS-SD containing $12 \%$ MD showed the highest $\mathrm{L}$ value indicating maximum deviation from the greenish colour of pulp due to addition of various additives and treatment given. The addition of varying levels of MD did not affect $\mathrm{a}_{\mathrm{w}}$ values of BFMS samples. The powder samples obtained after drying differed significantly $(\mathrm{P}<0.05)$ in $\mathrm{a}_{\mathrm{w}}$ values based on the content of MD present. The $\mathrm{a}_{\mathrm{w}}$ of BFMS-SD varied between 0.205 to 0.311 depending on the content of MD. BFMS powder is stable with respect to lipid oxidation, non-enzymatic browning, enzyme activity, and of course, the various microbial parameters with water activity in the range mentioned. As $a_{w}$ increases, the
Table 1 Proximate Composition and Quality characteristics of butter fruit milk shake (BFMS)

\begin{tabular}{lc}
\hline Quality Parameter & BFMS* \\
\hline Moisture content (\%) & $79.6 \pm 0.5$ \\
Ash (\%) & $3 \pm 0.04$ \\
Protein $(\%)$ & $2.4 \pm 0.02$ \\
Fat & $6 \pm 0.1$ \\
Carbohydrate (\%) & $9 \pm 0.2$ \\
Acidity (\% citric acid) & $1.03 \pm 0.03$ \\
pH & $6.3 \pm 0.1$ \\
TSS(Brix) & $17 \pm 1$ \\
\hline
\end{tabular}

*Values shown are mean \pm standard deviation of 6 samples

probability of the food product deterioration increases (Rahman, 2007). The stability of food with respect to oxidative changes is maximum at 0.4 and is in the $\mathrm{a}_{\mathrm{w}}$ range 0.2 to 0.6 Water activity less than 0.2 or higher than 0.6 has an adverse effect on the oxidative stability of the product (Rahman, 2010). As avocado pulp contains high-fat content compared to other fruit pulps, the oxidative stability of the product is of great significance. Water activity is a crucial aspect that determines shelf life. The maltodextrin added powder was found to have good stability than plain BFMS powder. It was observed that when the level of maltodextrin was increased, the water activity reduced; hence the product become more shelf-stable.

\section{Sorption isotherms}

The correlation between water activity $\left(\mathrm{a}_{\mathrm{w}}\right)$ and water content is complex. An increase in $a_{w}$ is usually be associated with by arise in water content, however in a non-linear pattern. This correlation between $\mathrm{a}_{\mathrm{w}}$ and moisture content at a given temperature is called the moisture sorption isotherm. These curves are determined experimentally and constitute the fingerprint of a food system. Isotherms can be employed to help predict product stability over time in different storage conditions. The knowledge and understanding of sorption isotherms are extremely crucial in food processing for the design and optimization of drying equipment, design of packages, predictions of quality, stability, shelf-life, and for calculating moisture changes that may occur during storage. Equilibrium moisture content for avocado milkshake powders added with varying levels of maltodextrin were plotted against at the six water activities. The sorption isotherms showed an increase in equilibrium moisture content with increasing water

Table2 Color and water activity values of spray dried avocado milkshake (BFMS)powder containing varying levels of maltodextrin (MD)

\begin{tabular}{lllll}
\hline Avocado milk shake Powder & $\mathrm{L}^{*}$ & $\mathrm{a}^{*}$ & $\mathrm{~b}^{*}$ & Water activity \\
\hline BFMS-SD 2\% MD & $85.46 \pm 0.2$ & $-4.51 \pm 0.01$ & $21.41 \pm 0.1$ & $0.311 \pm 0.05$ \\
BFMS-SD 6\% MD & $85.5 \pm 0.1$ & $-2.59 \pm 0.02$ & $17.55 \pm 0.1$ & $0.27 \pm 0.01$ \\
BFMS-SD 12\% MD & $87.24 \pm 0.2$ & $-2.81 \pm 0.01$ & $15.84 \pm 0.05$ & $0.205 \pm 0.02$ \\
\hline
\end{tabular}

*Values shown are mean \pm standard deviation of 3 samples 


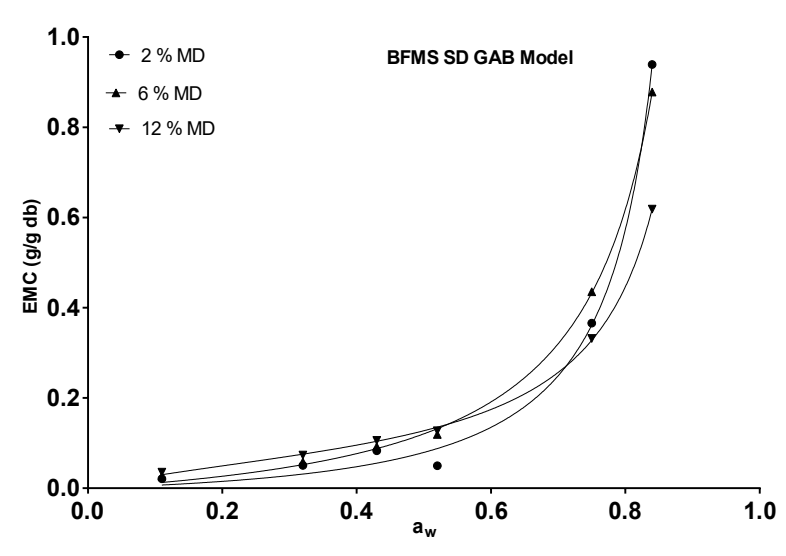

Fig 1. Water sorption isotherms (GAB Model) of spray dried avocado milkshake powder (BFMS-SD), formulated with 2, 6 and $12 \%$ maltodextrin (MD)

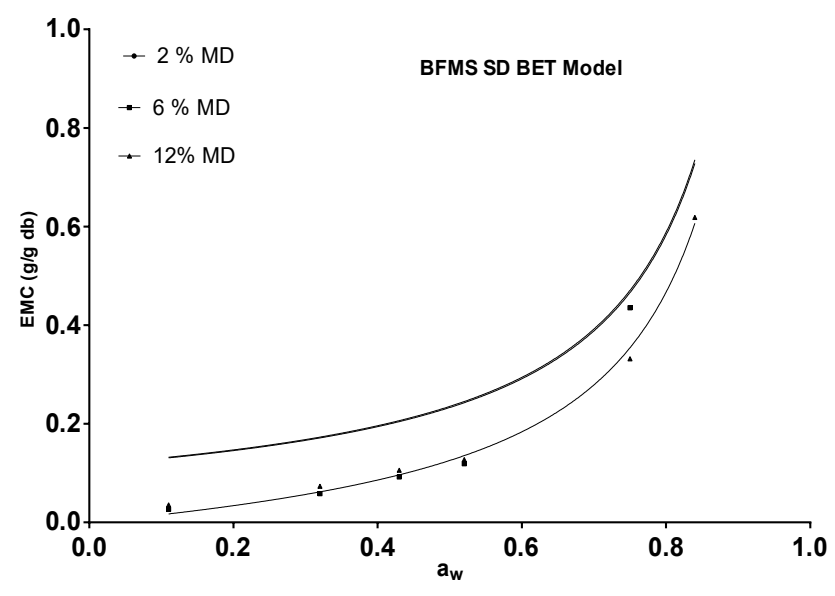

Fig 2. Water sorption isotherms (BET Model) of spray dried avocado milkshake powder (BFMS-SD), formulated with 2, 6 and $12 \%$ maltodextrin (MD)

Table 3 Estimated parameters of GAB and BET models fitted to sorption data of spray dried avocado milkshake (BFMS)powder produced with different levels of maltodextrin (MD)

\begin{tabular}{llllllll}
\hline $\begin{array}{l}\text { Avocado milk shake } \\
\text { Powder }\end{array}$ & \multicolumn{3}{c}{ GAB } & \multicolumn{3}{c}{ BET } \\
\cline { 2 - 7 } & $\mathrm{Xm}$ & $\mathrm{C}$ & $\mathrm{k}$ & $\mathrm{R}^{2}$ & $\mathrm{Xm}$ & $\mathrm{C}$ & $\mathrm{R}^{2}$ \\
BFMS-SD 2\% MD & 0.0970 & 0.4992 & 1.0870 & 0.9957 & 0.1165 & -9.452 & 0.7944 \\
BFMS-SD 6\% MD & 0.1311 & 0.7219 & 1.0420 & 0.9992 & 0.1177 & -2.473 & 0.8653 \\
BFMS-SD 12\% MD & 0.0726 & 4.3410 & 1.0550 & 0.9995 & 0.1114 & 1.293 & 0.9949 \\
\hline
\end{tabular}

activity, at constant temperature. These isotherms can be classified as type III, according to Brunauer's classification, characteristic of non-porous or macroporous solids due to weak gas-solid interactions. The weakness causes uptake at lower water activity to be small. But once a water molecule has become adsorbed, the adsorbate- adsorbate forces will promote the adsorption of further water molecules and the resulting isotherms will become convex to pressure axis. The sorption isotherms fitted to GAB and BET models are presented in Figure 1 and 2. These curves are used to estimate the coefficients of two sorption models.

At a given water activity, EMC of the samples decreased with increasing levels of MD. Similar results were reported by other workers (Gabas et al. 2007; Mara and Maria, 2005). The presence of additives in the avocado milkshake powder probably modified the balance of hydrophilic/hydrophobic sites, promoting a decreased amount of sorbed water as reported by Perez-Alonso et al. (2006) for pure and blended carbohydrate polymers.

Similar isotherms were observed for protein hydrolysates from fish, pineapple, tomato pulp, West Indian cherry and lactose hydrolysed skim milk powders (Gabas et al. 2007; Shrestha et al. 2007). This type of curve was also observed by, Gabas et al. (2007) for vacuum dried pineapple containing maltodextrin and gum Arabic, and Kurozawa et al. (2009) for spray-dried chicken meat hydrolysate protein produced with these same carrier agents.

Experimental data of the sorption isotherms for spray-dried avocado milkshake powder produced with different levels of carrier agent maltodextrin was fitted to GAB and BET models. Each model was tested for adequacy and goodness of fit by determining the coefficient $\mathrm{R}^{2}$. The estimated parameters with the coefficient of determination $\left(\mathrm{R}^{2}\right)$ are presented in Table 3 .

Both BET and GAB models showed a good fit to experimental data, with high $\mathrm{R}^{2}$. The results showed that for all the different MD concentrations studied, the GAB model presented a better fit than the BET model, with coefficient of determination close to unity. Hence GAB model gives a better prediction of the adsorption behavior of both SD avocado milk shake powder. As the $\mathrm{R}^{2}$ values calculated by the BET model were lower, this model lacked prediction accuracy than GAB model for the sorption data of powdered avocado milkshake. This can be explained due to the limiting values for the constants $\mathrm{C}_{\mathrm{BET}}$ as suggested by Lewicki (1997), established on the mathematical analysis of the model. For sigmoidal type curves, constants values are in the range $0.24 \ll \mathrm{K}_{\mathrm{GAB}} 1$ and $5.6 \mathrm{C}_{\mathrm{GAB}}$, to guarantee a relatively good description of the isotherms and to fulfill the requirements of the GAB model, as well as assuring that the calculated monolayer 
Fig 3. Thermograms of spray dried avocado milkshake powder (BFMS-SD), formulated with 2, 6 and $12 \%$ maltodextrin (MD)

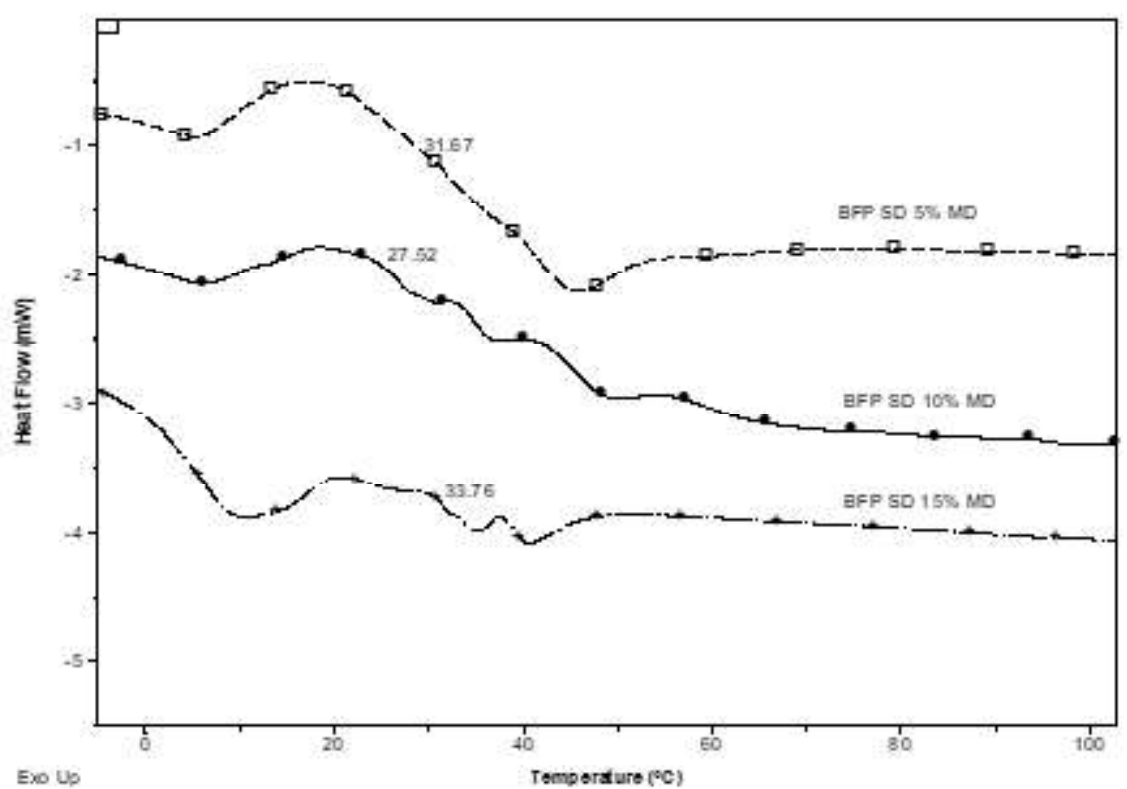

Fig. 4 Thermograms of spray dried avocado milkshake powder (BFMSSD) equilibrated at different water activities and formulated with $12 \%$ maltodextrin

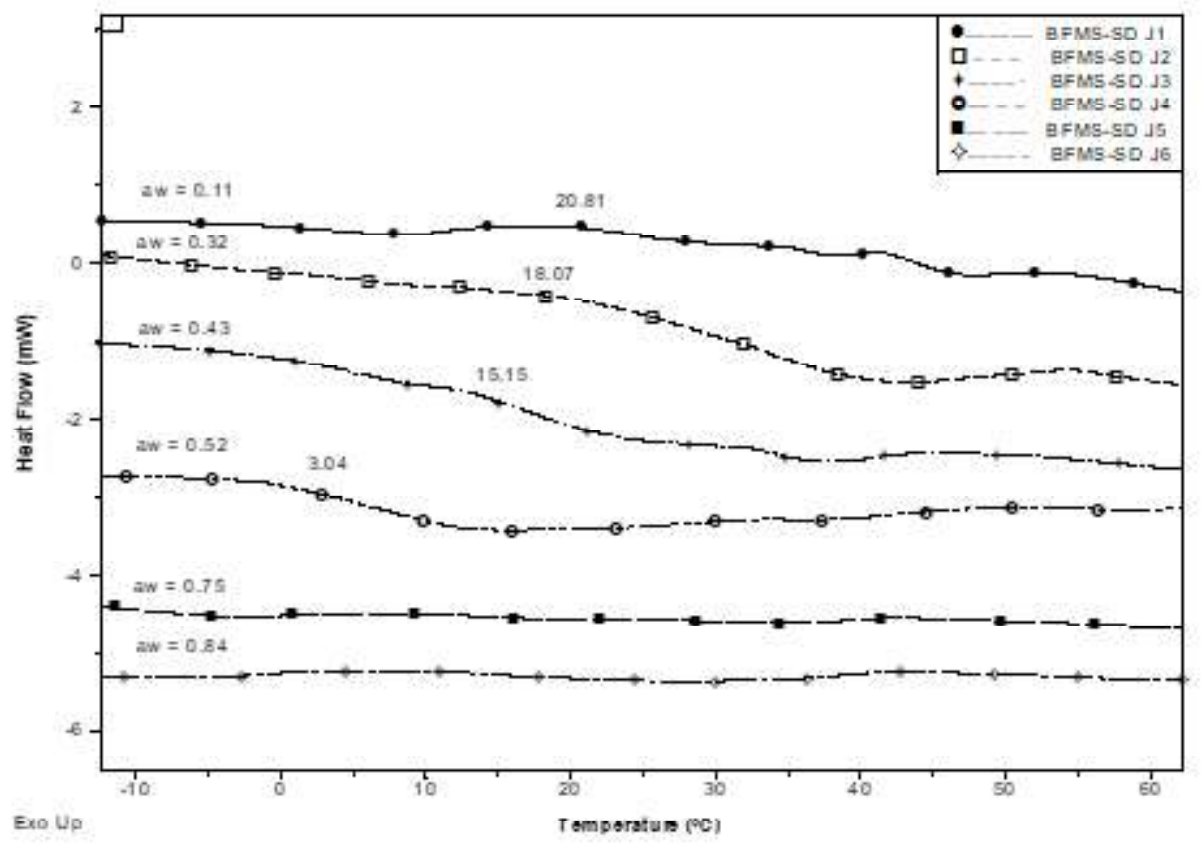

moisture content values differed by no more than $15.5 \%$ from the true monolayer capacity.

For samples containing $12 \% \mathrm{MD}$, both the models showed good degree of fit to predict the sorption behavior. Both BET and GAB models are based on the monolayer moisture concept and give the value of monolayer moisture content of the material $(\mathrm{Xm})$, considered as the safe moisture for dried foods during preservation, while most other models lack this parameter. The monolayer moisture content (Xm) indicates the amount of water that is strongly adsorbed to specific sites at the food surface and is considered an important value to assure food stability. Xm values were obtained from the linear plot of $\mathrm{a}_{\mathrm{w}}$ versus 1 / $\left(\operatorname{EMC}^{*}\left(\mathrm{a}_{\mathrm{w}}-1\right)\right)$ and calculated using the equation $\mathrm{Xm}=1 /(\mathrm{s}+\mathrm{i})$ where $\mathrm{s}$ is the slope and $\mathrm{i}$ is the $\mathrm{y}$-intercept. TheXm values obtained by fitting BET \& GAB models to sorption data of BFMS$\mathrm{SD}$ containing varying levels of MD varied from 0.07 to $0.13 \mathrm{~g} / \mathrm{g}$ $\mathrm{db}$.

\section{DSC thermograms of BFMS powder}

BFMS-SD samples containing varying levels of MD were analysed in the temperature range $-30^{\circ} \mathrm{C}$ to $110^{\circ} \mathrm{C}$ at the rate of 10 

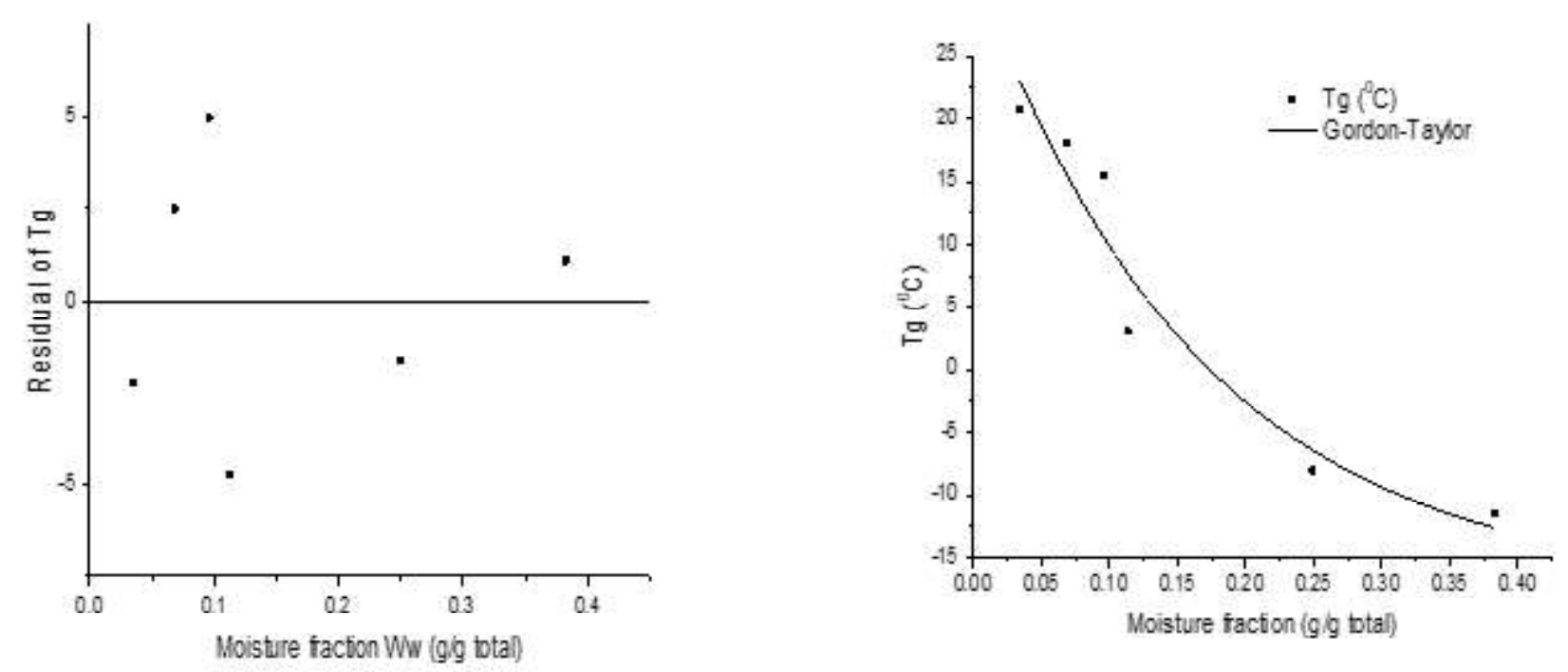

Fig. 5 Residual plots obtained for spray dried avocado milkshake powder (BFMS-SD) and Gordon -Taylor fitting for moisture vsTg values containing $12 \%$ maltodextrin (MD)

${ }^{\circ} \mathrm{C} / \mathrm{min}$ and the results obtained are summarized in this section. The thermograms of spray-dried BFMS powders containing 2, 6 and $12 \% \mathrm{MD}$ had $\mathrm{Tg}$ values $26.1,27.52$, and 33.9 respectively showing increase with increasing levels of $\mathrm{MD}$ in the blend. MD upto $12 \%$ was required for spray dried samples to avoid stickiness during drying and also to increase the product yield. A satisfactory product cannot be obtained with $2 \%$ MD with spray drying technique.

\section{DSC thermograms of BFMS samples equilibrated at different RH conditions}

DSC thermograms of selected BFMS samples (SD sample containing $12 \% \mathrm{MD}$ ) were analyzed to study the plasticizing effect of water. In general, the thermograms showed the typical second-order transition that produces a step change in the heat flow due to changes in heat capacity at the temperature of phase transition. The glass transition temperature was taken as the midpoint of the glass transition. Glass transition temperature of powders obtained with different drying methods equilibrated at different $\mathrm{RH}$ conditions varied from -8 to $20.81^{\circ} \mathrm{C}$. The changes in exothermic and endothermic phase transitions due to changing moisture content in BFMS-SD samples were analysed.

$\mathrm{Tg}$ values for samples equilibrated at different water activities were correlated with sorption data (Figure 4).Tg decreased with increasing water activity. Plasticisation by an increasing water content results in the decrease of the glass transition. At the critical water activity, the $\mathrm{Tg}$ is decreased to storage temperature and further increases in $\mathrm{a}_{\mathrm{w}}$ result in a decrease in viscosity of particles, stickiness, caking, and rapid increases in rates of lactose crystallisation and diffusion-controlled reactions. Two endotherms and one exotherm were observed in most of the thermograms analysed for plasticizing effect of water. At higher water activities the onset of crystallization differed significantly whereas the changes in melting curves were not significant due to the plasticizing effect of water. The crystallization peaks and melting peaks shifted to lower temperatures with increasing moisture content indicating the lower stability of samples containing high moisture. These differences were highly significant in samples equilibrated at $\mathrm{a}_{\mathrm{w}}$ of 0.75 and above.

The correlation between $\mathrm{Tg}$ and the water fraction present in the sample was fitted using the Gordon-Taylor model (Figure 5) showing satisfactory values of $\mathrm{R}^{2}(>0.85)$. The sticky-point temperature is normally about $10-23^{\circ} \mathrm{C}$ higher than the glass transition temperature and, in spray drying, particles which are above this temperature stick to the dryer wall and degrade, and/ or clump together, adversely affecting the free-flowing property. In the case of avocado milkshake powder, considering its low sugars and acids level, the sticky-temperature is much higher than $85^{\circ} \mathrm{C}$ (the outlet air temperature) and that would result in a high degree of stickiness and thus help in a significant powder yield. There spray drying could be efficiently employed for the production of avocado milkshake powder. In a study on skim milk powder, it is reported that the glass transition temperature was found to be virtually the same as the sticky-point temperature measured using a thermo-mechanical test.It has been shown in previous reports that $\mathrm{Ts}$ and $\mathrm{Tg}$ (glass transition temperature) are very closely correlated, and both can be used to assess stickiness of powder materials (Ozmen and Langrish, 2002; 2006). As Tg is dependent on sugar and acid composition, stickty point (Ts) also varies based on these.

\section{Product stability based on water activity and glass transition}


Fig. 6Variation of glass transition temperature and equilibrium moisture content with water activity for spray dried avocado milkshake powder (BFMS-SD) produced with 12\% maltodextrin (MD)

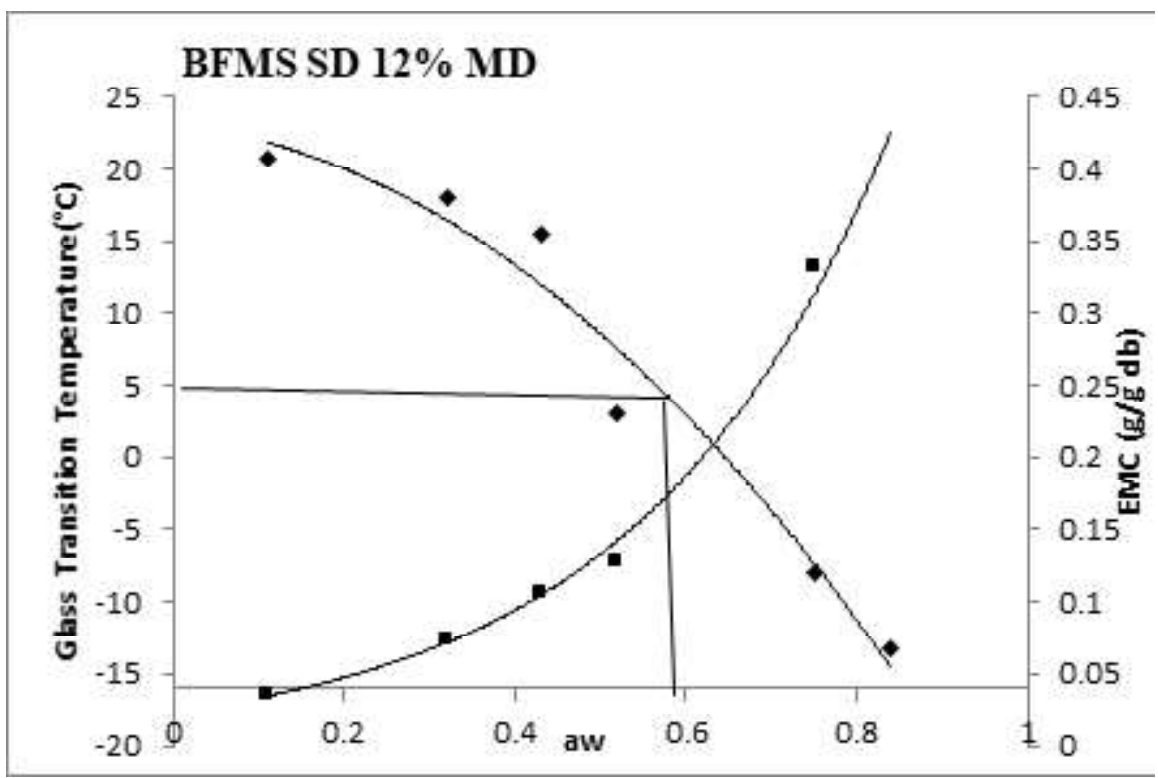

\section{Conclusions}

Among all the samples prepared by spray drying with varying levels of MD, avocado milkshake powder with $12 \% \mathrm{MD}$ was found to be the best without any stickiness and bitter taste. The colour was also acceptable for this sample. GAB model was found to be adequate $\left(\mathrm{R}^{2}=0.99\right)$ to describe the experimental sorption data obtained for the spray-dried avocado milkshake powder. The glass transition temperature was determined for different water activities, in which an increase in moisture content caused a significant decrease in the glass transition temperature. The data for Tg fitted well with the Gordon-Taylor model. $\left(\mathrm{R}^{2}=0.89\right)$. The addition of maltodextrin increased the $\mathrm{Tg}$ and consequently contributed to the stability of the powder. These data could be used to assist the proper spray drying operational conditions with respect to stickiness and storage behaviour of the milk shake of a fat rich fruit like avocado. Likewise, powder with 12\% maltodextrin was more stable at a higher relative humidity (critical water activity 0.6 ), which contributes to the prevention of caking and diffusion controlled deteriorative processes. This combined plot of $\mathrm{Tg}$ and sorption is a better tool for determining the ideal storage conditions for the product.

\section{References}

Adhikari B, Howes T, Bhandari BR, Troung V (2004) Effect of addition of maltodextrin on drying kinetics and stickiness of sugar and acid-rich foods during convective drying: experiments and modelling. J Food Eng 62: 53-68

AOAC (2005). Official methods of analysis of the association of official analytical chemists international. USA: Maryland

Bhandari BR, Hartel RW (2005) Phase transitions during food powder production and powder stability

Brunauer S, Emmett PH, Teller E (1938) Adsorption of gases in multimolecular layers. J Am Chem Soc 60: 309-319 
Cano-Chauca, M, Stringheta, PC, Ramos AM, Cal-Vidal J (2005) Effect of the carriers on the microstructure of mango powder obtained by spray drying and its functional characterization. Innov Food Sci Emerg Technol 6: 420-428

DorantesL, Parada L, Ortiz A (2004) Avocado: post-harvest operation. AGST/FAO.

Duester KC (2000) Avocados a look beyond basic nutrition for one of nature's whole foods. Nutr Today 35: 151-157

Gabas AL, Telis VRN, Sobral PJA, Telis-Romero J (2007) Effect of maltodextrin and arabic gum in water vapor sorption thermodynamic properties of vacuum dried pineapple pulp powder. J Food Eng 82: 246-252

Gordon M,TaylorJS(1952)Ideal copolymers and the second order transitions of synthetic rubbers. I. Non crystalline copolymers. J Appl Chem 2: 493-500

Johari GP, Hallbrucker A, Mayer E (1987) The glass-liquid transition of hyper quenched water. Nat 330: 552-553

KhalloufiS, El MaslouhiY, Ratti C (2000) Mathematical model for prediction of glass transition temperature of fruit powders. J Food Sci 65: 842-848

KurozawaLE, Park KJ, Hubinger MD (2009) Effect of maltodextrin and gum arabic on water sorption and glass transition temperature of spray dried chicken meat hydrolysate protein. J Food Eng 91: 287296

LewickiPP(1997) The applicability of the GAB model to food water sorption isotherms. Int J Food Sci Technol 32: 553-557

Mara RighettoA, Maria Netto F (2005) Effect of encapsulating materials on water sorption, glass transition and stability of juice from immature acerola. Int J Food Prop 8: 337-346.

Moraga G, Martýnez-Navarrete N, Chiralt A (2004) Water sorption isotherms and glass transition in strawberries: influence of pretreatment. J Food Eng 62: 315-321

Moraga G, Martínez-Navarrete N, Chiralt A (2006) Water sorption isotherms and phase transitions in kiwifruit. J Food Eng 72: 147156
Ozmen L, Langrish TAG (2002) Comparison of Glass Transition Temperature and Sticky Point Temperature for Skim Milk Powder. Drying Technol20: 1177-1192

Pérez-Alonso C, Beristain CI, Lobato-Calleros C, Rodríguez-Huezo ME, Vernon-Carter EJ (2006) Thermodynamic analysis of the sorption isotherms of pure and blended carbohydrate polymers. J Food Eng 77: $753-760$

Rahman MS (2010) Food stability determination by macro-micro region concept in the state diagram and by defining a critical temperature. J Food Eng 99: 402-416

Rahman MS (2007) Handbook of Food preservation. CRC press.

Rainey C, Affleck M, Bretschger K, Alfin-Slater RB (1994) The California avocado: a new look. Nutr Today 29: 23-27

Ranganna S (2004) Handbook of analysis and quality control for fruit and vegetable products. Tata McGraw-Hill Education.

Reineccius GA (1991) Carbohydrates for flavor encapsulation. Food Technol 45: 144-146

Roos YH (1995) Food components and polymers. Phase transitions in foods, $109-156$

Roos Y, Karel M (1991) Amorphous state and delayed ice formation in sucrose solutions. Int J Food Sci Technol 26: 553-566

Shivakumar KM, Chetana R, Reddy SY (2012) Preparation and properties of encapsulated fat powders containing speciality fat and $\omega /$ PUFArich oils. Int J Food Prop 15: 412-425

Shrestha AK, HowesT, Adhikari BP, Bhandari BR (2007) Water sorption and glass transition properties of spray dried lactose hydrolysed skim milk powder. Lwt-Food Sci Technol 40: 1593-1600

Silva MA, Sobral PJA, Kieckbusch TG (2006) State diagrams of freezedried camu-camu (Myrciariadubia (HBK) Mc Vaugh) pulp with and without maltodextrin addition. J Food Eng 77: 426-432.

Xiong H, Tang HM, Xiong XQ, Zheng WW (2004) Nutritional and functional properties of cream powder of imitation mother's dairy [J]. China Dairy Industry, 8 www.cnki.com.cn 